\title{
Adapting SPICE for Development of a Reference Model for Building Information Modeling - BIM-CAREM
}

\author{
Gokcen Yilmaz $^{1(\bowtie)}$, Asli Akcamete ${ }^{2}$, and Onur Demirors ${ }^{3}$ \\ ${ }^{1}$ Pamukkale University, 20020 Denizli, Turkey \\ gokcenyilmaz@gmail.com \\ 2 Middle East Technical University, 06800 Ankara, Turkey \\ akcamete@metu.edu.tr \\ ${ }^{3}$ Izmir Institute of Technology, 35430 Izmir, Turkey
}

\begin{abstract}
Building Information Modelling (BIM) is highly adopted by Architecture, Engineering, Construction and Facilities Management (AEC/FM) companies around the world due to its benefits such as improving collaboration of stakeholders in projects. Effective implementation of BIM in organizations requires assessment of existing BIM performances of AEC/FM processes. We developed a reference model for BIM capability assessments based on the metamodel of the ISO/IEC 330xx (the most recent version of SPICE) family of standards. BIM-CAREM can be used for identifying the BIM capabilities of the AEC/FM processes. The model was updated iteratively based on the expert reviews and an exploratory case study, and was evaluated via four explanatory case studies. The assessment results showed that the BIM-CAREM is capable of identifying BIM capabilities of specific processes. In this paper, we present how we utilized ISO/IEC 330xx for developing BIM-CAREM as well as the iterations of the model and one of the explanatory case studies as an example.
\end{abstract}

Keywords: Building Information Modeling $\cdot$ ISO/IEC 330xx BIM capability $\cdot$ SPICE

\section{Introduction}

Building Information Modeling (BIM) is a business process for generating and leveraging building data to design, construct and operate the building during its lifecycle [1]. Usage of BIM brings significant benefits in the facility life cycle. For example, it allows earlier collaboration of multiple design disciplines and use of the design model as basis for fabricated components [2]. Due to such benefits, many initiatives have been undertaken for adopting BIM as an emerging technology in various countries such as the US, the UK, Finland, Norway and Hong Kong [3].

Even after the adoption of BIM, Architecture, Engineering, Construction and Facilities Management (AEC/FM) organizations need to evaluate the performances of their BIM usages. Hence, various BIM capability and maturity models have been developed for meeting the different assessment purposes [4]. We identified six prevalent BIM capability and maturity models in the literature and each model was 
explained in detail in the review paper of Yilmaz et al. [5]. Later, we extended this literature review by adding two recently created models and these models were evaluated based on the identified criteria [6]. Users need to analyze these models in detail to choose the most appropriate model for their purposes. According to Wu et al. [4], most of these models share common metrics which are clustered into several categories; i.e. process, technology, organization, human and standard. This shows that models in the literature were not developed based on established standards.

As a response to these limitations, a reference model for BIM capability assessments namely BIM-CAREM was developed [6, 7]. BIM-CAREM was developed based on the meta-model of the ISO/IEC 330xx family of standards [8] which includes definitions and requirements for developing process reference models and measurement frameworks. This standard has been widely adapted into different domains such as software testing [9] and information security [10]. During the development, BIMCAREM was updated iteratively through conducting expert reviews and an exploratory case study [6]. Finally, it was evaluated via explanatory case studies in four different AEC/FM companies [7].

The aim of this paper is to discuss how we used the principles and requirements explained in the ISO/IEC 330xx family of standards for creating the BIM-CAREM. We also present which parts of the standard were adapted and which parts were used without any change. We explained the benefits of using principles explained in ISO/IEC 330xx family of standards as well as the challenges that were faced during creation of BIM-CAREM. Moreover, iterations of the model via expert reviews and evaluation of the model via explanatory case studies are explained.

The literature review and research methodology for development of BIM-CAREM are presented in Sects. 2 and 3, respectively. Structure of BIM-CAREM is described in Sect. 4. While an explanatory case study is explained in Sect. 5 as an example, conclusions are discussed in Sect. 6.

\section{Literature Review}

Eight models, which were identified via systematic literature review and explained in detail in the review paper of Yilmaz et al. [5], were included in the development process of BIM-CAREM. These eight models were; Capability Maturity Model of the National Institute of Building Sciences [11], BIM Proficiency Matrix [12], BIM QuickScan [13], Virtual Design and Construction Scorecard [14], Organizational BIM Assessment Profile [15], VICO BIM Scorecard [16], BIM Maturity Matrix [17], and Multifunctional BIM Maturity Matrix [18]. These eight models were analyzed based on the five criteria and explained in the paper of Yilmaz et al. [6]. According to these findings, the limitations of these models are summarized as below.

Each model has been developed to meet specific assessment purposes. Similarly, according to the literature review of Giel et al. [19], models were developed to assess one of the three capabilities; organizational, project, and individual. Hence, selecting appropriate models for specific assessment purposes is time-consuming. Models were developed by inspiring from each other, since they share many common metrics. Metrics of these models can be clustered into four groups which are; process, 
organization (standard and personnel), technical (hardware and software) and data. There is not a broadly accepted and commonly used model in the literature, since most of these approaches were not developed based on established standards. Most of these models do not cover all BIM uses performed by BIM practitioners existing in the AEC/FM industry. Hence, while some of the models are more suitable to assess BIM performance of designer firms, some can be used for measuring BIM performance of facility owners. The models do not support BIM performance assessments of specific processes, such as those of construction. Moreover, metrics belong to process category are not comprehensive to cover all AEC/FM facility life cycle stages. These limitations are explained in the $\mathrm{PhD}$ dissertation of Yilmaz [7] in more detail.

Due to its adaptable structure, meta-model of ISO/IEC 330xx family of standards [8] was used to develop a reference model for BIM capability assessment called BIMCAREM to eliminate the limitations given above. The recent ISO/IEC 330xx family of standards, which is one of the well-known capability and maturity models in the software engineering, replaced the ISO/IEC 15504 Software Process Improvement and Capability dEtermination (SPICE) standard which provides guidance on how to utilize process assessment for conducting process improvement. Two of the parts belonging to ISO/IEC 330xx family of standards, which are ISO/IEC 33003 and ISO/IEC 33004, are important for users who want to develop process reference models and process measurement frameworks. While ISO/IEC 33003 [20] provides requirements for developing process measurement frameworks, ISO/IEC 33004 [21] gives requirements for development of process reference, process assessment and maturity models.

The ISO/IEC 15504 and ISO/IEC 330xx have been taken as a basis for creating new capability and maturity models required in different domains and sectors. ISO/IEC 33063 [9] is a process assessment model for software testing and contains a set of process quality characteristics to be used for assessing capabilities of software testing processes. Automotive SPICE [22] is developed conformant with the requirements of a process assessment model defined in the ISO/IEC 15504-2 [23]. It is used to assess the software development in automotive industry [22]. MDevSPICE [24] is developed to meet the specific safety-critical and regulatory requirements of the medical device domain. It consists of process reference model and process assessment model. Process reference model includes 24 processes from system level and supporting processes described in ISO/IEC 12207 [25]. Process assessment model consists measurement framework with six levels of capability which is based on the ISO/IEC 15504-2 [26]. SPICE4Space [27] is based on the ISO/IEC 15504-5 [28], and it includes assessment model for space software practices.

The AgilityMod [29] is developed based on the ISO/IEC 15504-2 [26] for assessing the agility levels of software development projects. In this study, the core of the agile projects, which are called aspects, are determined and defined as well as the agility levels and their related aspect attributes [29]. Aspects are sets of interrelated and interacting activities. A web-based agility assessment tool is created based on the AgilityMod to facilitate automatic agility assessment and the tool is tested though multiple case studies [30]. In relation with AgilityMod a measurement capability assessment method is also developed [31]. This model enables assessing the measurement capability of aspects (sets of interrelated and interacting activities) defined by 
AgilityMod. The measurement capability levels and their associated generic practices are created based on the ISO/IEC 330xx too [31].

ISO/IEC 15504 or ISOIEC/330xx is adapted to other non-software domains as well. For example, ISO/IEC 33052 [32] is a process reference model for information security management and describes the processes related to information security management system. ISO/IEC 33072 [10] introduces an information security management process assessment model which is composed of both a process reference model and a process measurement framework. ISO/IEC 33071 [33] introduces an integrated process assessment model for enterprise processes which integrates selected process models and standards into a single model. A SPICE based Government Process Capability Determination Model namely Gov-PCDM is developed for assessing the capabilities of the processes of public organizations [34]. Definitions of the Financial and Physical Resource Management (PFPRM) processes are exemplified based on the requirements defined in the ISO/IEC 15504-2 [26]. The model has been evaluated in three different organizations. The results showed that the measurement framework defined is capable of identifying the capability levels and of the proposed PFPRM process definitions and creating roadmaps for process improvements [34].

\section{Research Methodology for Development of the BIM- CAREM}

We developed the BIM-CAREM based on the meta-model of ISO/IEC 330xx family of standards [8]. Later, we updated the model in terms of the feedbacks gathered via expert reviews and an exploratory case study. Finally, the model was evaluated through four explanatory case studies. The research tasks followed for developing the BIMCAREM are depicted briefly in Fig. 1.

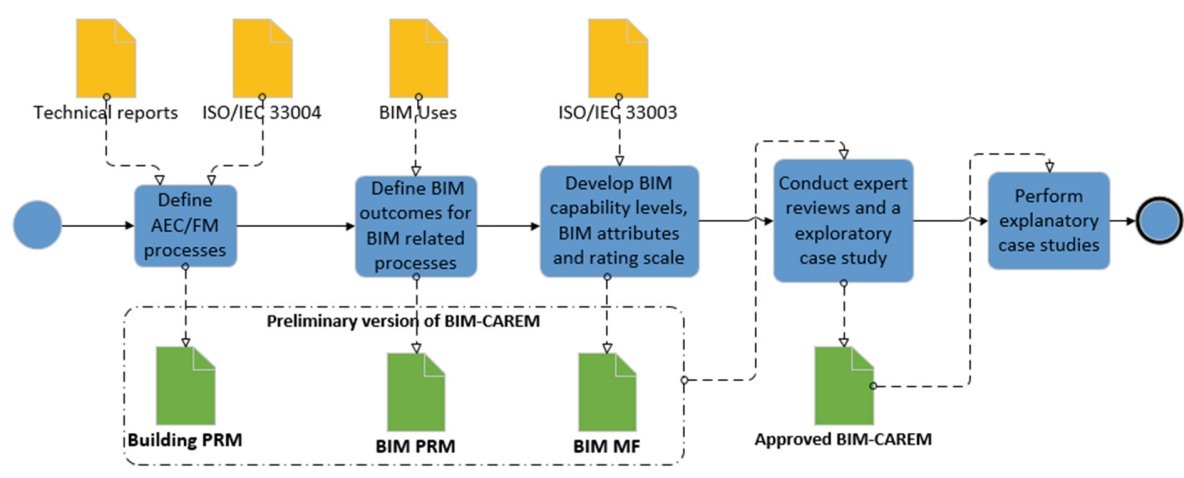

Fig. 1. The research tasks and the parts of the standard used in these tasks

The Building PRM and the BIM PRM were developed based on the principles explained in the ISO/IEC 33004-Requirements for Process Reference, Process Assessment and Maturity [21]. We have also used ISO/IEC 24774- Systems and 
software engineering - Life cycle management - Guidelines for Process Description [35] as an exemplar model. The BIM MF was created in conformance to the ISO/IEC 33003 - Requirements for Process Measurement Frameworks [20] as depicted in the Fig. 1. We also used, the ISO/IEC 15504-5 An Exemplar Process Assessment Model [28] and the ISO/IEC 33020- Process Measurement Framework for Assessment of Process Capability [36] for analyzing the example process descriptions and process capability levels. Table 1 presents the terminology which is used in MF of the BIMCAREM in relation with the terminology of SPICE.

Table 1. Terminology used in the BIM MF

\begin{tabular}{l|l}
\hline Terminology in ISO/IEC 33003 and ISO/IEC 33004 & Terminology in BIM-CAREM \\
\hline PRM & Building/BIM PRM \\
\hline Process Purpose & Process Purpose \\
\hline Process Outcome & Process/BIM Outcome \\
\hline Base Practice & Base Practice \\
\hline Work Product & Work Product \\
\hline Process MF & BIM MF \\
\hline Process Capability Levels & BIM Capability Levels \\
\hline Process Attribute & BIM Attribute \\
\hline Process Attribute Outcome & BIM Attribute Outcome \\
\hline Generic Practice & Generic Practice \\
\hline Generic Work Product & Generic BIM Work Product \\
\hline Generic Resource & Generic Resource \\
\hline Rating Scale & Rating Scale \\
\hline
\end{tabular}

\subsection{Creating the Building/BIM PRMs and the BIM MF}

According to the requirements defined in the ISO/IEC 33004 [21], the domain of the process reference models is the AEC/FM industry. Building PRM was developed before the BIM PRM. In order to decide which facility life cycle stages were included in the Building PRM, RIBA Plan of Work [37] was used. Conceptual Planning (P), Architectural Design (ARCH D), Structural Design (STR D), Building Services Design (BS D), Geotechnical Design (GEO D), Construction (C) and the Facility Management (FM) were included in the Building PRM. Key AEC/FM processes of each phase included in Building PRM were determined by taking two important technical reports $[38,39]$ as basis. Building PRM consists of 37 key AEC/FM processes. In order to define all AEC/FM processes systematically, a definition template was created based on the requirements stated in ISO/IEC 33004 [21] and ISO/IEC 24774 [35]. This template is composed of process purpose, process outcomes, base practices and work products. Each of the 37 AEC/FM processes in Building PRM was defined by using this template. An example process definition of Building PRM can be seen in Fig. 3.

$\mathrm{BIM}$ aspect was not included in the AEC/FM process definitions, since the reports, which were taken as basis for creating process definitions, have definitions of traditional AEC/FM processes and do not include BIM. Therefore, BIM related AEC/FM 
processes were marked and included in the BIM PRM. BIM PRM has 28 processes of Building PRM in total. In other words, BIM PRM was a subset of Building PRM. Each process in BIM PRM was defined based on the process purpose and BIM outcomes instead of process outcomes. BIM outcomes were defined based on the BIM uses identified by analyzing various resources such as surveys, reports and articles identified in the literature. Details about creation of BIM outcomes can be found in the $\mathrm{PhD}$ dissertation of Yilmaz [7]. Process purpose and base practices of the processes included in the BIM PRM remained the same as that of the processes included in Building PRM. An example process description belonging to BIM PRM can be seen in Fig. 4.

After BIM capability levels and their BIM attributes were created based on the principles given in ISO/IEC 33003 [20], rating scale given in ISO/IEC 33020 [36] was used without any modification. Four BIM capability levels were defined since they were sufficient without omitting any significant type of BIM utilization in AEC/FM industry. Two BIM attributes for each BIM capability levels were defined based on the recurring key words identified in the BIM uses. These BIM uses were selected from various resources such as surveys, guidelines and articles, and then collected in an Excel workbook. Recurring nouns and verbs were identified via Natural Language Analysis (NLA) method [40], and frequent words were used to create BIM attributes. Details about creation of BIM capability levels and their BIM attributes can be found in the dissertation [7]. Generic BIM work products and generic resources were developed based on the recurring keywords identified [7], BIM handbook [2] and various BIM guidelines. Rating scale of BIM-CAREM was same as the one defined in the ISO/IEC 33020 [36]. Validity and reliability of the BIM capability levels and their associated BIM attributes were established based on the expert reviews and the exploratory case study which are explained in Sect. 3.2.

\subsection{Updating the BIM-CAREM}

BIM-CAREM was updated based on the reviews of four experts who are working in the AEC/FM industry either as BIM managers or as BIM consultants. Three versions of BIM-CAREM were created. The first version of BIM-CAREM was reviewed by Expert 1 and second version of BIM-CAREM was then created. BIM A1.2 BIM Skills was added as BIM attribute for Level 1-Performed BIM. Although, this is not a requirement of performed level stated in the ISO/IEC 33003 [20], BIM skilled employees are necessary for performance of each process. BIM A3.1 Corporate-wide BIM Deployment was also added as a BIM attribute for Level 3-Optimized BIM.

Third version of BIM-CAREM was developed after expert reviews with Expert 2, Expert 3 and the exploratory case study. According to feedback of Expert 2, the terminology used in defining design processes of BIM PRM was corrected. Additionally, each BIM outcome was tagged with one of the two values namely "essential BIM use" and "enhanced BIM use" as defined in National BIM Guide for Owners [41]. According to reviews of Expert 3, one BIM attribute outcome of BIM A3.1 Corporatewide BIM Deployment was updated. The previous version of this BIM attribute outcome could have been used for assessing processes belong to a specific type of organization. The latest version of the attribute became more generic to be used for measuring processes belong to various types of organizations such as designers and 
general contractors. An exploratory case study was performed to identify whether further updates were required or not. Architectural, structural and building services processes of an engineering and design firm located in Istanbul were assessed by using BIM-CAREM. According to the findings, identified BIM capability levels were the same as the levels expected by the interviewees. Details about the exploratory case study can be found in Yilmaz et al. [6]. We have not added or removed any BIM attributes within this iteration.

Finally, third version of BIM-CAREM was approved by Expert 1 and Expert 4, since most of their comments were covered before. In other words, the third version of BIM-CAREM is the final and approved version of BIM-CAREM. We have not added or removed any BIM capability levels. Four levels of BIM capability were approved by all of the experts. It has been stated that the model has a systematic approach for conducting assessments.

\section{BIM-CAREM}

The BIM-CAREM is composed of two dimensions which are BIM process dimension and the BIM capability dimension. As presented in Fig. 2, while BIM process dimension consists of the Building PRM and BIM PRM, the BIM capability dimension contains BIM MF. Details about the BIM-CAREM such as definitions of BIM capability levels can be found in the $\mathrm{PhD}$ dissertation of Yilmaz [7].

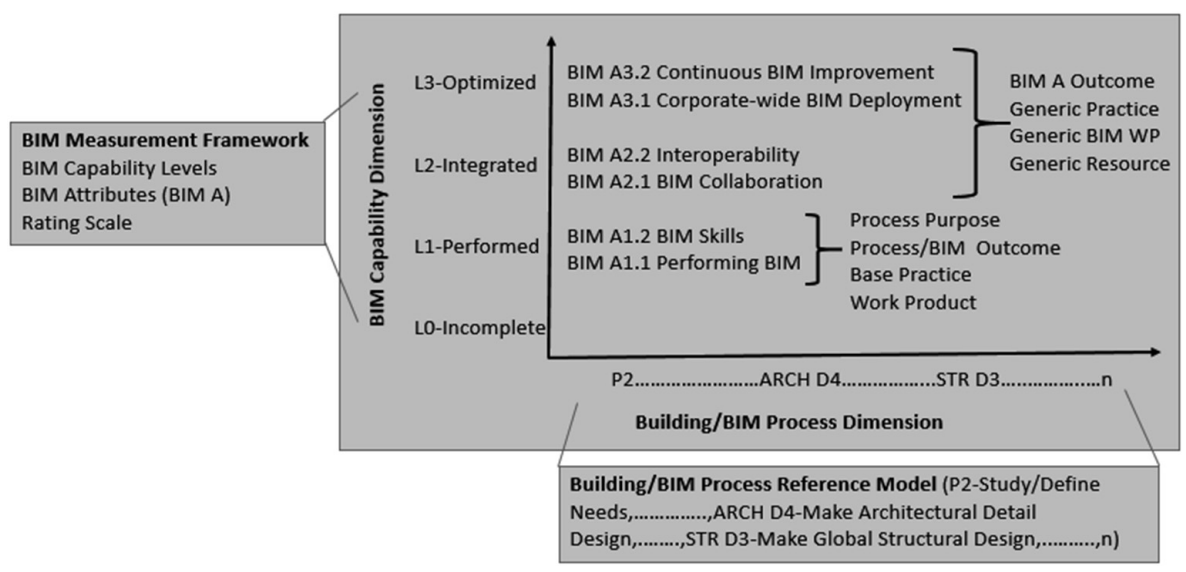

Fig. 2. The BIM-CAREM and its components

BIM-CAREM was developed to be used for assessing BIM capabilities of AEC/FM processes of facility life cycle. BIM-CAREM allows users to make formal assessments of AEC/FM processes by using BIM MF. AEC/FM processes to be measured can be selected from BIM PRM which is a subset of Building PRM. The BIM MF consists of four BIM capability levels and the BIM attributes which are used to characterize BIM capability of an implemented process. 
While Building PRM consists of 37 key AEC/FM processes, BIM RPM contains 28 of these processes. In other words, only BIM related processes of Building PRM were included in the BIM PRM. The list of AEC/FM processes included in Building PRM are given in Table 2. Processes which are related to BIM was marked with "Y" and included in BIM PRM as well.

Table 2. Key AEC/FM processes included in Building PRM/BIM PRM

\begin{tabular}{|c|c|c|c|}
\hline Phase ID & Process ID & Process name & $\begin{array}{l}\text { Rel. to BIM? } \\
(\mathrm{Y} / \mathrm{N})\end{array}$ \\
\hline \multirow[t]{6}{*}{ Conceptual Planning (P) } & P1 & Assign Planning Team & $\mathrm{N}$ \\
\hline & P2 & Study/Define Needs & $\mathrm{Y}$ \\
\hline & P3 & Study Feasibility & Y \\
\hline & P4 & Develop Program & $\mathrm{N}$ \\
\hline & P5 & $\begin{array}{l}\text { Develop Project } \\
\text { Execution Plan }\end{array}$ & $\mathrm{Y}$ \\
\hline & P6 & Select And Acquire Site & $\mathrm{Y}$ \\
\hline \multirow[t]{5}{*}{ Architectural Design (ARCH D) } & ARCH D1 & Draw Up Brief & $\mathrm{N}$ \\
\hline & ARCH D2 & Draw Up Program & $\mathrm{Y}$ \\
\hline & ARCH D3 & Make Global Design & $\mathrm{Y}$ \\
\hline & ARCH D4 & Make Detail Design & $\mathrm{Y}$ \\
\hline & ARCH D5 & $\begin{array}{l}\text { Do Design Tasks } \\
\text { During Construction }\end{array}$ & $\mathrm{Y}$ \\
\hline \multirow{5}{*}{$\begin{array}{l}\text { Structural/Building } \\
\text { Services/Geotechnical Design } \\
\text { (STR/BS/GEO D) }\end{array}$} & $\begin{array}{l}\text { STR/BS/GEO } \\
\text { D1 }\end{array}$ & Draw Up Brief & $\mathrm{N}$ \\
\hline & $\begin{array}{l}\text { STR/BS/GEO } \\
\text { D2 }\end{array}$ & Draw Up Program & $\mathrm{N}$ \\
\hline & $\begin{array}{l}\text { STR/BS/GEO } \\
\text { D3 }\end{array}$ & Make Global Design & $\mathrm{Y}$ \\
\hline & $\begin{array}{l}\text { STR/BS/GEO } \\
\text { D4 }\end{array}$ & Make Detail Design & Y \\
\hline & $\begin{array}{l}\text { STR/BS/GEO } \\
\text { D5 }\end{array}$ & $\begin{array}{l}\text { Do Design Tasks } \\
\text { During Construction }\end{array}$ & $\mathrm{Y}$ \\
\hline \multirow[t]{4}{*}{ Construction $(\mathrm{C})$} & $\mathrm{C} 1$ & $\begin{array}{l}\text { Acquire Construction } \\
\text { Services }\end{array}$ & $\mathrm{Y}$ \\
\hline & $\mathrm{C} 2$ & $\begin{array}{l}\text { Plan And Control The } \\
\text { Work }\end{array}$ & Y \\
\hline & $\mathrm{C} 3$ & Provide Resources & Y \\
\hline & $\mathrm{C} 4$ & Build Facility & $\mathrm{Y}$ \\
\hline \multirow[t]{7}{*}{ Facilities Management (FM) } & FM1 & Plan/Control Facility & $\mathrm{Y}$ \\
\hline & FM2 & Manage Operations & $\mathrm{Y}$ \\
\hline & FM3 & $\begin{array}{l}\text { Monitor Facility } \\
\text { Conditions And } \\
\text { Systems }\end{array}$ & $\mathrm{Y}$ \\
\hline & FM4 & $\begin{array}{l}\text { Evaluate Conditions } \\
\text { And Detect Problems }\end{array}$ & $\mathrm{Y}$ \\
\hline & FM5 & Develop Solutions & Y \\
\hline & FM6 & Select Plan Of Action & $\mathrm{Y}$ \\
\hline & FM7 & Implement Plan & $\mathrm{Y}$ \\
\hline
\end{tabular}


Each process in Building PRM was defined in terms of the process purpose, process outcomes, base practices and work products. Process purpose indicates the high level objective of performing the process [8]. Process outcome is an observable and assessable result of the successful achievement of the process purpose [8]. Base practice is an activity or a set of activities which contributes to process purpose achievement [8]. Work product is an artefact associated with the execution of the processes in Building PRM. Figure 3 presents 'Build Facility' belonging to Building PRM as an example process description.

\begin{tabular}{|c|c|c|c|}
\hline Process ID & \multicolumn{3}{|c|}{ C4 } \\
\hline Process name & \multicolumn{3}{|c|}{ Build Facility } \\
\hline Process purpose & \multicolumn{3}{|c|}{$\begin{array}{l}\text { The purpose of the Build Facility is to construct the facility according to the design using available } \\
\text { resources. }\end{array}$} \\
\hline Process outcomes & \multicolumn{3}{|c|}{$\begin{array}{l}\text { As a result of successful implementation of Build Facility: } \\
\text { 1. Daily distribution plan is created based on the construction execution plan. } \\
\text { 2. Resources are distributed to the appropriate work areas. } \\
\text { 3. Facility elements are constructed by consuming resources. } \\
\text { 4. Completed work is checked regarding to quantity, quality, and location of the product and } \\
\text { constructed facility is approved. } \\
\text { 5. Constructed building systems are tested, permits are obtained, facility is started up and facility is } \\
\text { handed over to the owner. }\end{array}$} \\
\hline Base practices & \multicolumn{3}{|c|}{$\begin{array}{l}\text { 1. Plan the daily work: Utilize instructions for conducting the daily work based on the construction } \\
\text { execution plan. (Outcome 1) } \\
\text { Distribute the resources: Transport the needed resources to the appropriate work areas based } \\
\text { on the daily distribution plan. (Outcome 2) } \\
\text { 3. Do the physical work: Construct the facility elements. (Outcome 3) (BIMout 1,2,3) } \\
\text { 4. Inspect and approve the work: Check the completed work to assure that the quantity, quality, } \\
\text { and location of the product is sufficient and that the contract requirements were fulfilled and } \\
\text { approve the constructed facility. (Outcome 4) (BIMout 4) } \\
\text { Turn over the completed work: Test and adjust the building systems, obtain the occupancy } \\
\text { permit, start up the facility and submit operation information to the owner. (Outcome 5) } \\
\text { (BIMout 5) }\end{array}$} \\
\hline \multicolumn{4}{|c|}{ Work Products } \\
\hline \multicolumn{3}{|c|}{ 1. Progress information (Outcome 1) } & 12. Environment \\
\hline \multicolumn{3}{|c|}{ 2. Construction execution plan } & 13. Partially consumed resources (Outcome 3 ) \\
\hline \multicolumn{3}{|c|}{ 3. Daily plan (Outcome 1) } & 14. Completed facility elements (Outcome 3 ) \\
\hline \multicolumn{3}{|c|}{ 4. Environment and governmental requirements } & 15. Inspection records information (Outcome 4) \\
\hline \multicolumn{3}{|l|}{ 5. Field experience } & 16. Daily approval plan \\
\hline \multicolumn{3}{|c|}{ 6. Available resources and mobilized site } & 17. Approved work (Outcome 4) \\
\hline \multicolumn{3}{|c|}{ 7. Distribution progress information (Outcome 2) } & 18. Inspections \\
\hline \multicolumn{3}{|c|}{ 8. Distributed resources (Outcome 2) } & \\
\hline \multicolumn{3}{|c|}{ 9. Distribution priorities } & $\begin{array}{l}\text { 19. Handover information (Outcome 5) } \\
\text { 20. Startup plan }\end{array}$ \\
\hline \multicolumn{3}{|c|}{ 10. Work progress information (Outcome 3 ) } & 21. Post construction information (Outcome 5) \\
\hline \multicolumn{3}{|l|}{ 11. Daily work plan } & 22. Facility (Outcome 5) \\
\hline \multicolumn{3}{|c|}{ Base Practice } & puts \\
\hline \multicolumn{2}{|c|}{ BP1 } & & 4,5 \\
\hline \multicolumn{2}{|c|}{ BP2 } & & 6,9 \\
\hline \multicolumn{2}{|c|}{ BP3 } & & 1,12 \\
\hline & & & 6,18 \\
\hline & & & \\
\hline
\end{tabular}

Fig. 3. Process description of Build Facility in Building PRM

BIM PRM was derived from Building PRM and created to define BIM related AEC/FM processes in terms of BIM. Each process in BIM PRM was defined in terms of the process purpose, BIM outcomes, base practices, and work products. Figure 4 presents the same process, which is Build Facility, included in the BIM PRM. While process purpose and base practices of Build Facility remained the same, BIM outcomes 


\begin{tabular}{|c|c|c|}
\hline Process ID & \multicolumn{2}{|l|}{ C4 } \\
\hline Process name & \multicolumn{2}{|l|}{ Build Facility } \\
\hline Process purpose & \multicolumn{2}{|c|}{$\begin{array}{l}\text { The purpose of the Build Facility is to construct the facility according to the design using } \\
\text { available resources. }\end{array}$} \\
\hline BIM outcomes & \multicolumn{2}{|c|}{$\begin{array}{l}\text { As a result of successful implementation of Build Facility: } \\
\text { 1. Daily work is executed based on } 4 D \text { plan. } \\
\text { 2. } 3 \text { D location identification: Physical locations of elements on site are pinpointed for } \\
\text { 3. Fanstilty is constructed by using BIM. } \\
\text { 4. Quality assurance is conducted via BIM and site data such as pictures and point clouds. } \\
\text { 5. Operation data is handed over to the owner with BIM. }\end{array}$} \\
\hline \multicolumn{3}{|c|}{ BIM Work Products } \\
\hline 1. Facility (BIMou & & 4. Locations points (BIMout 2) \\
\hline \multicolumn{2}{|c|}{ 2. Progress information (BIMout 1) } & 5. Daily work (BIMout 1) \\
\hline \multicolumn{2}{|c|}{ 3. Quality assurance (BIMout 4) } & 6. Handover information (BIMout 5) \\
\hline
\end{tabular}

Fig. 4. Process description of Build Facility in BIM PRM

and BIM work products were defined for each process included in the BIM PRM. BIM outcome is an observable and assessable result of the successful achievement of the process purpose in terms of BIM. BIM work product is a BIM artefact associated with the execution of the BIM related processes included in the BIM PRM.

BIM MF has four BIM capability levels which are Level 0- Incomplete, Level 1Performed, Level 2-Integrated, and Level 3-Optimized. The BIM capability levels, and their BIM attributes are presented in Fig. 2 and Table 3.

Table 3. No of BIM attributes and associated BIM attribute outcomes

\begin{tabular}{|c|c|c|}
\hline $\begin{array}{l}\text { BIM } \\
\text { Cap. Lev. }\end{array}$ & BIM A & BIM attribute outcomes \\
\hline \multirow{4}{*}{$\begin{array}{l}\text { Level 1- } \\
\text { Performed }\end{array}$} & BIM A1.1 Performing BIM & (a) The process achieves its defined BIM outcomes \\
\hline & \multirow[t]{3}{*}{ BIM A1.2 BIM Skills } & (a) Staff with BIM skills and/or BIM experience are employed \\
\hline & & (b) Employees are supported in taking BIM trainings \\
\hline & & $\begin{array}{l}\text { (c) BIM related processes are assigned to the BIM trained } \\
\text { and/or BIM experienced employees or peer learning is } \\
\text { encouraged }\end{array}$ \\
\hline \multirow[t]{5}{*}{$\begin{array}{l}\text { Level 2- } \\
\text { Integrated }\end{array}$} & \multirow[t]{4}{*}{$\begin{array}{l}\text { BIM A2.1 BIM } \\
\text { Collaboration }\end{array}$} & $\begin{array}{l}\text { (a) Requirements and strategies are defined for supporting BIM } \\
\text { collaboration between internal and external parties }\end{array}$ \\
\hline & & $\begin{array}{l}\text { (b) Requirements and strategies are defined for exchanging the } \\
\text { model and the facility information between phases and } \\
\text { processes }\end{array}$ \\
\hline & & (c) Defined BIM collaboration strategies are implemented \\
\hline & & $\begin{array}{l}\text { (d) Defined exchange strategies of the model and the facility } \\
\text { information are implemented }\end{array}$ \\
\hline & BIM A2.2 Interoperability & $\begin{array}{l}\text { (a) Interoperable formats are made available and used to } \\
\text { support data exchange between BIM software and other } \\
\text { construction software applications }\end{array}$ \\
\hline \multirow[t]{2}{*}{$\begin{array}{l}\text { Level 3- } \\
\text { Optimized }\end{array}$} & \multirow[t]{2}{*}{$\begin{array}{l}\text { BIM A3.1 Corporate-wide } \\
\text { BIM Deployment }\end{array}$} & $\begin{array}{l}\text { (a) Model is used for all processes and embraced by all team } \\
\text { members }\end{array}$ \\
\hline & & $\begin{array}{l}\text { (b) Required facility information for different processes are } \\
\text { extracted from the model and provided for the use of all team } \\
\text { members }\end{array}$ \\
\hline
\end{tabular}


Table 3. (continued)

\begin{tabular}{l|l|l}
\hline $\begin{array}{l}\text { BIM } \\
\text { Cap. Lev. }\end{array}$ & BIM A & BIM attribute outcomes \\
\hline & & $\begin{array}{l}\text { (c) Change management and synchronization of the model are } \\
\text { established and the model updates are tracked }\end{array}$ \\
\hline $\begin{array}{l}\text { (d) BIM objects and facility information are collected in a } \\
\text { library for reusing this information in future projects }\end{array}$ \\
\cline { 2 - 3 } $\begin{array}{l}\text { BIM A3.2 Continuous BIM } \\
\text { Improvement }\end{array}$ & $\begin{array}{l}\text { (a) A feedback mechanism is created to identify common } \\
\text { causes of variations in BIM usage }\end{array}$ \\
$\begin{array}{l}\text { (b) Improvement opportunities, which are derived from } \\
\text { feedback mechanism and from new BIM technology trends and } \\
\text { best practices, are identified }\end{array}$ \\
\hline $\begin{array}{l}\text { (c) An implementation strategy is established to achieve BIM } \\
\text { improvement objectives }\end{array}$ \\
\hline
\end{tabular}

BIM capability level indicates an organization's BIM leverage capability in their building processes and is characterized by BIM attributes. BIM capability levels except from Level 0, related BIM attributes and their BIM attribute outcomes are presented in Table 3. BIM attribute is an observable phenomenon to be measured for identifying BIM capability level of a construction organization's process in formal BIM capability assessments. BIM attribute outcome (AO) is the observable result of a BIM attribute achievement.

Example generic BIM work products and generic resources with respect to the number of the BIM attribute outcomes are given in Table 4. The names of the BIM attribute outcome are presented in the table. Generic BIM work product (WP) is a BIM artefact associated with the execution of a process. Generic resource (GR) is resources which are required for executing a process.

Rating scale of the BIM-CAREM is the same as the one given in the ISO/IEC 33020 [36]. Rating scale is a rating schema to be used in BIM capability assessments for identifying the degree of achievement of BIM attributes. The BIM attributes are rated based on the below rating scale:

- N Not Achieved 0 to $\leq 15 \%$ achievement,

- P Partially Achieved $>15 \%$ to $\leq 50 \%$ achievement,

- L Largely Achieved $>50 \%$ to $\leq 85 \%$ achievement, and

- F Fully Achieved $>85 \%$ to $\leq 100 \%$ achievement.

In order to calculate the composite ratings of the BIM attributes, we followed the procedures of aggregation using medians as explained in ISO/IEC 33020 [36]. 
Table 4. Example generic BIM WPs and example GRs defined for each of the BIM attribute outcome

\begin{tabular}{|c|c|c|}
\hline $\begin{array}{l}\text { No of } \\
\text { BIM } \\
\text { AO }\end{array}$ & Example generic BIM WP & Example GR \\
\hline 1.1a) & BIM work products & $\begin{array}{l}\text { BIM authoring tools for model } \\
\text { generation, analysis Tools }\end{array}$ \\
\hline 1.2a) & Job advertisement descriptions & BIM expert \\
\hline $1.2 \mathrm{~b})$ & BIM training records & BIM training budget \\
\hline $1.2 \mathrm{c})$ & $\begin{array}{l}\text { A strategy for assigning the BIM roles and } \\
\text { responsibilities }\end{array}$ & Employees with BIM skills \\
\hline 2.1a) & $\begin{array}{l}\text { Documents, reports and etc. which defines BIM } \\
\text { collaboration strategies and/or procedures }\end{array}$ & $\begin{array}{l}\text { Construction information and } \\
\text { documentation standards and } \\
\text { guidelines }\end{array}$ \\
\hline $2.1 \mathrm{~b})$ & BIM Execution Plan & Common data environments \\
\hline 2.1c) & Shared models for coordination & Collaboration tools \\
\hline 2.1d) & $\begin{array}{l}\text { Existence of defined standard data formats for } \\
\text { exchanging the model and the facility information }\end{array}$ & Process owners and stakeholders \\
\hline 2.2a) & $\begin{array}{l}\text { Models and facility information represented with } \\
\text { interoperable formats }\end{array}$ & Interoperable formats \\
\hline 3.1a) & Company-wide BIM execution plan & Virtual Reality Services \\
\hline $3.1 \mathrm{~b})$ & Model views & Model View Definitions \\
\hline $3.1 c)$ & $\begin{array}{l}\text { Version control of the model according to change } \\
\text { requests }\end{array}$ & BIM server \\
\hline $3.1 \mathrm{~d})$ & Custom libraries such as $3 \mathrm{D}$ object libraries & $\begin{array}{l}\text { Databases to store, gather and integrate } \\
\text { the model and facility information }\end{array}$ \\
\hline $3.2 \mathrm{a})$ & $\begin{array}{l}\text { Mechanism for identifying and documenting BIM } \\
\text { variations }\end{array}$ & $\begin{array}{l}\text { Software for identification of problems } \\
\text { in BIM utilization }\end{array}$ \\
\hline $3.2 b)$ & Innovation meetings within the organization & $\begin{array}{l}\text { Technical reports about new BIM } \\
\text { technologies }\end{array}$ \\
\hline $3.2 \mathrm{c})$ & $\begin{array}{l}\text { Strategy to implement BIM improvement } \\
\text { objectives }\end{array}$ & Employees such as BIM experts \\
\hline
\end{tabular}

\section{A Case Study}

Final version of the BIM-CAREM was evaluated via four explanatory case studies. The goal of these case studies was to determine the applicability of the BIM-CAREM for identifying the BIM capabilities of AEC/FM organizations. Case study conducted with Company B is presented as an example in this section. Company B is a structural design and engineering firm located in Ankara. Structural design of steel and concrete frames were evaluated within the context of the case study. A semi-structure interview was performed with manager of the company, three civil engineers and two technicians. Pre-defined interview questions were asked for primary data collection, and notes were taken. Secondary data was collected via direct observations of assessment indicators such as 3D models created by using BIM and structural analysis of the models. Additionally, whole interview was audio recorded. Case report of Company B was written based on the audio record, notes taken during the interview, and the secondary data collected. Rating of each BIM attribute was given based on this report. We used the rating scale explained in Sect. 3. It is four points ordinal scale which 
includes Not achieved (N-red), Partially achieved (P-yellow), Largely achieved (Lblue) and Fully achieved (F-green) and Not Applicable (NA-grey). In Table 5, the colored schema of the assessment ratings for Case Study 1 are provided.

Table 5. BIM attribute ratings of structural design of steel and reinforced concrete frames in Company B

\begin{tabular}{|l|c|c|c|c|c|c|}
\hline & \multicolumn{2}{|c|}{$\begin{array}{c}\text { Level 1- } \\
\text { Performed BIM }\end{array}$} & \multicolumn{2}{c|}{$\begin{array}{c}\text { Level 2- } \\
\text { Integrated BIM }\end{array}$} & \multicolumn{2}{c|}{$\begin{array}{c}\text { Level 3- } \\
\text { Optimized BIM }\end{array}$} \\
\hline Phase / BIM Attribute & $\begin{array}{c}\text { BIM } \\
\text { A1.1 }\end{array}$ & $\begin{array}{c}\text { BIM } \\
\text { A1.2 }\end{array}$ & $\begin{array}{c}\text { BIM } \\
\text { A2.1 }\end{array}$ & $\begin{array}{c}\text { BIM } \\
\text { A2.2 }\end{array}$ & $\begin{array}{c}\text { BIM } \\
\text { A3.1 }\end{array}$ & $\begin{array}{c}\text { BIM } \\
\text { A3.2 }\end{array}$ \\
\hline $\begin{array}{l}\text { STR D-Structural Design of } \\
\text { Steel Frames }\end{array}$ & F & F & L & F & L & P \\
\hline $\begin{array}{l}\text { STR D-Structural Design of } \\
\text { Reinforced Concrete Frames }\end{array}$ & F & F & L & F & P & P \\
\hline
\end{tabular}

Figure 5 shows the achieved BIM capability levels of the assessed two processes which are structural design of steel and concrete frames. For a BIM capability level to be reached, all BIM attributes should be largely or fully achieved.

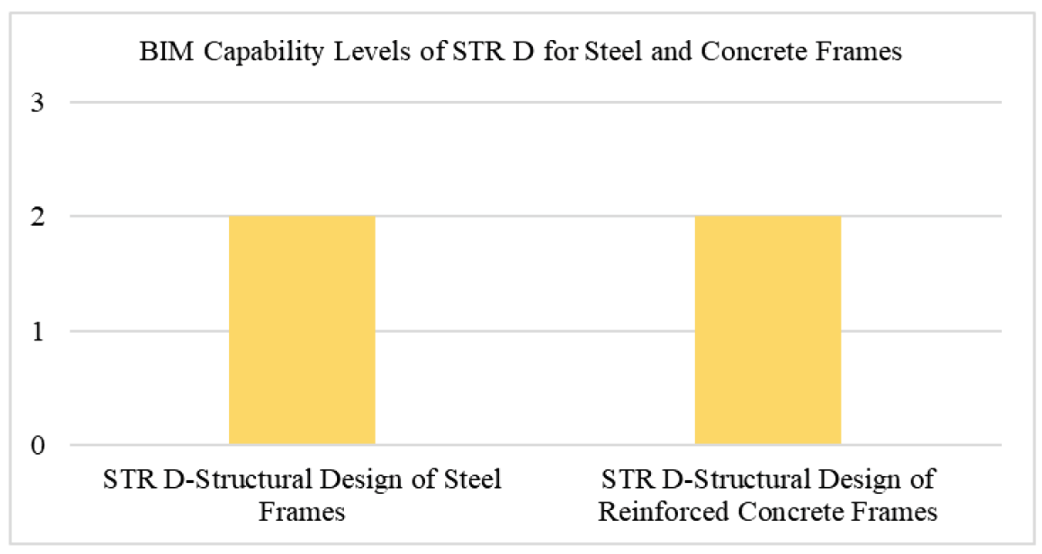

Fig. 5. Achieved BIM capability levels of structural design of steel and concrete frames

After the assessment, a questionnaire was applied to the interviewees to validate the findings of the case study. We asked them four questions which are given in Table 6 and requested them to rate each question from 1 to 5 .

According to their answers and the ratings given, we concluded that BIM-CAREM can be used for identifying BIM capabilities of AEC/FM processes. Details of the rest of the four case studies can be found in the PhD dissertation of Yilmaz [7]. 
Table 6. Ratings given by interviewees for assessment results found via BIM-CAREM

\begin{tabular}{l|l}
\hline Question & Rating \\
\hline BIM-CAREM is capable of identifying BIM capabilities of AEC/FM processes & 4 \\
\hline $\begin{array}{l}\text { BIM-CAREM can be utilized for identifying BIM capabilities of AEC/FM } \\
\text { processes }\end{array}$ & 5 \\
\hline $\begin{array}{l}\text { BIM-CAREM is helpful to understand BIM related gaps of AEC/FM processes by } \\
\text { identifying their BIM capabilities }\end{array}$ & 5 \\
$\begin{array}{l}\text { To what extent do the assessment results match with the existing BIM capabilities } \\
\text { of your processes? }\end{array}$ & 5 \\
\hline
\end{tabular}

\section{Conclusions}

We followed the principles explained in the ISO/IEC 330xx family of standards to develop the BIM-CAREM. The model was updated iteratively through expert review and the exploratory case study, and later it was evaluated via explanatory case studies. It would have taken more time to develop such a holistic model, if we have not used the structure of the ISO/IEC 330xx which has significant amount of information for the users who will adapt it into different domains.

The ISO/IEC 33004 [21] was used for creating the Building/BIM PRM, since the important points and requirements of developing a process reference model are explained in this part. We did not face any significant difficulty in applying the procedures given in both of these standards. However, we put most of our effort in describing the process outcomes/BIM outcomes and the base practices. The Building/BIM PRM contains process definitions in terms of process purpose and process/BIM outcomes, as well as base practices and work products.

We followed the procedures explained in the ISO/IEC 33003 [20] for creating the BIM MF. This part of the standard contains sections explaining how to define capability levels and their associated attributes. We also inspired from the ISO/IEC 33020 [36] while generating definitions of BIM capability levels and their associated BIM attributes. Determination of the BIM capability levels and the BIM attributes took time, since they were updated in terms of expert reviews and an exploratory case study, as explained in Sect. 3.2. The BIM MF includes BIM capability levels, BIM attributes, and outcomes of these BIM attributes resultant of performing generic practices. The generic BIM work products and the generic resources were also defined within the context of the BIM MF. The elements given in ISO/IEC 33020 [36] are the examples for us while creating the generic BIM work products and generic resources.

We used the same procedures explained in the ISO/IEC 33003 [20] without any change for creating the rating scale and choosing the aggregation method. Thus, using the structure of the ISO/IEC 330xx saved significant amount of time. Nevertheless, a paper [42], which is about aggregation methods of constructs such as BIM attributes in qualitative research, was helpful to understand the aggregation methods of higher order constructs.

Various statistical methods are suggested for testing the validity and the reliability of the constructs, but further reading is required to understand and apply the right 
statistical test. The BIM capability levels and BIM attributes were validated by BIM experts who rated the BIM capability levels and their associated BIM attributes via an online questionnaire. The results of the online questionnaire can be found in the Yilmaz et al. [6]. Considering the results of the multiple case studies, we conclude that BIMCAREM can be used to identify the BIM capability levels of the AEC/FM processes.

Acknowledgement. Attendance to SPICE 2018 is funded by Pamukkale University with project number 2018KKP219.

\section{References}

1. NBIMS: National BIM Standard - United States ${ }^{\circledR}$ Version 3 - Scope (2015). https://www. nationalbimstandard.org/. Accessed 01 Jul 2018

2. Eastman, C., Teicholz, P., Sacks, R., Liston, K.: BIM Handbook. Wiley, Hoboken (2008)

3. Edirisinghe, R.: Comparative analysis of international and national level BIM standardization efforts and BIM adoption. In: 32nd CIB W78 Conference (2015)

4. Wu, C., et al.: Overview of BIM maturity measurement tools. J. Inf. Technol. Constr. 22, 34-62 (2016)

5. Yilmaz, G., Akcamete, A., Demirors, O.: A review on capability and maturity models of building information modelling. In: Lean and Computing in Construction (2017)

6. Yilmaz, G., Akcamete, A., Demirors, O.: BIM-CAREM: a reference model for BIM capability assessments. Autom. Constr., Under Review, July 2018

7. Yilmaz, G.: BIM-CAREM: a reference model for building information modelling capability assessment (2017). http://library.metu.edu.tr/search/?searchtype=X\&searcharg=BIMCAREM\&searchscope $=15$. Accessed $30 \mathrm{Jul} 2018$

8. ISO/IEC: ISO/IEC 33001 Information technology - Process assessment - Concepts and terminology (2015). https://www.iso.org/obp/ui/\#iso:std:iso-iec:33001:ed-1:v1:en. Accessed $01 \mathrm{Jul} 2018$

9. ISO/IEC: ISO/IEC 33063 Information technology - Process assessment - Process assessment model for software testing (2015). https://www.iso.org/obp/ui/\#iso:std:iso-iec: 33063:ed-1:v1:en. Accessed 01 Jul 2018

10. ISO/IEC: ISO/IEC 33072 Information technology - Process assessment - Process capability assessment model for information security management (2016). https://www.iso.org/obp/ui/ \#iso:std:iso-iec:ts:33072:ed-1:v2:en. Accessed 01 Jul 2018

11. NBIMS: National BIM Standard United States ${ }^{\circledR}$ Version 3 - Minimum BIM (2015). https:// www.nationalbimstandard.org. Accessed 01 Jul 2018

12. IU Arhictect's Office: BIM Proficiency Matrix (2009). http://www.iu.edu/ vpcpf/ consultant-contractor/standards/bim-standards.shtml

13. BIM Supporters B.V.: BIM QuickScan Tool (2010). https://app.bimsupporters.com/ quickscan/. Accessed 04 Apr 2018

14. Kam, C., Senaratna, D., Xiao, Y., McKinney, B.: The VDC Scorecard: Evaluation of AEC Projects and Industry Trends. CIFE Working Paper \#WP136 (2013). https://stacks.stanford. edu/file/druid:st437wr3978/WP136.pdf. Accessed 03 Jul 2018

15. PennState CIC: Organizational BIM Assessment Profile (2012). http://bim.psu.edu/ resources/owner/bim_planning_guide_for_facility_owners-version_2.0.pdf. Accessed 27 Jun 2018

16. VICO Software: VICO BIM Scorecard Survey. https://www.surveymonkey.com/r/ 9YCHVXC. Accessed 25 Aug 2017 
17. Succar, B.: Building information modelling maturity matrix. In: Handbook of Research on Building Information Modeling and Construction Informatics: Concepts and Technologies, pp. 65-103 (2010)

18. Liang, C., Lu, W., Rowlinson, S., Zhang, X.: Development of a multifunctional BIM maturity model. J. Constr. Eng. Manag. 142(11), 06016003 (2016)

19. Giel, B., McCuen, T.: MINIMUM BIM - 2nd Edn. Proposed Revision. Building Innovation, pp. 1-35 (2014)

20. ISO/IEC: ISO/IEC 33003 Information technology - Process assessment - Requirements for process measurement frameworks (2015). https://www.iso.org/obp/ui/\#iso:std:iso-iec:33003: ed-1:v1:en. Accessed 01 Jul 2018

21. ISO/IEC: ISO/IEC 33004 Information technology - Process assessment - Requirements for process reference, process assessment and maturity models (2015). https://www.iso.org/obp/ ui/\#iso:std:iso-iec:33004:ed-1:v2:en. Accessed 01 Jul 2018

22. Automative Sig: Automotive SPICE Process Assessment Model (2007). http://www. automotivespice.com/fileadmin/software-download/Automotive_SPICE_PAM_30.pdf. Accessed $01 \mathrm{Jul} 2018$

23. ISO/IEC: The ISO/IEC 15504 - 3 Information technology - Process assessment - Part 3: Guidance of performing an assessment (2012)

24. Zanoni, M., Perin, F., Fontana, F.A., Viscusi, G.: Development of MDevSPICE - the medical device software process assessment framework Marion. J. Softw. Evol. Process 26 (12), 1172-1192 (2014)

25. ISO/IEC: The ISO/IEC 12207 Systems and software engineering-Software life cycle processes (2008)

26. ISO/IEC: The ISO/IEC 15504 - 2 Information technology - Process assessment - Part 2: Performing an assessment (2012)

27. Cass, A., Völcker, C., Ouared, R., Dorling, A., Winzer, L., Carranza, J.M.: SPICE for SPACE trials, risk analysis, and process improvement. Softw. Process Improv. Pract. 9(1), 13-21 (2004)

28. ISO/IEC: The ISO/IEC 15504 - 5 Information technology - Process assessment - Part 5: An Exemplar Process Assessment Model (2006). https://www.iso.org/standard/60555.html. Accessed 03 Jul 2018

29. Top, O.O., Demirors, O.: A reference model for software agility assessment: AgilityMod. In: SPICE, pp. 145-158 (2015)

30. Adali, O.E., Top, O.O., Demirors, O.: Assessment of agility in software organizations with a web-based agility assessment tool. In: Proceedings of the 43rd Euromicro Conference on Software Engineering and Advanced Applications SEAA 2017, pp. 88-95 (2017)

31. Salmanoğlu, M., Coşkunçay, A., Yıldız, A., Demirörs, O.: An exploratory case study for assessing the measurement capability of an agile organization. Softw. Qual. Prof. 20(2), 3647 (2018)

32. ISO/IEC: ISO/IEC 33052 Information technology - Process reference model (PRM) for information security management (2016). https://www.iso.org/obp/ui/\#iso:std:iso-iec:ts: 33052:ed-1:v1:en. Accessed 01 Jul 2018

33. ISO/IEC: ISO/IEC 33071 Information technology - Process assessment - An integrated process capability assessment model for Enterprise processes (2016). https://www.iso.org/ obp/ui/\#iso:std:iso-iec:33071:ed-1:v1:en. Accessed 01 Jul 2018

34. Gökalp, E., Demirörs, O.: Model based process assessment for public financial and physical resource management processes. Comput. Stand. Interfaces 54, 186-193 (2017)

35. IEEE: ISO/IEC TR 24774 - Systems and Software Engineering Life Cycle Management: Guidelines for Process Description (2012). https://www.iso.org/obp/ui/\#iso:std:iso-iec:tr: 24774:ed-2:v1:en. Accessed 01 Jul 2018 
36. ISO/IEC: ISO/IEC 33020 Information technology - Process assessment - Process measurement framework for assessment of process capability (2015). https://www.iso.org/ obp/ui/\#iso:std:iso-iec:33020:ed-1:v1:en. Accessed 01 Jul 2018

37. RIBA: RIBA Plan of Work (2013). https://www.ribaplanofwork.com/. Accessed 09 Nov 2017

38. Technical Research Center of Finland: Construction Process Model (1997). https://www.vtt. fi/inf/pdf/tiedotteet/1997/T1845.pdf. Accessed 01 Jul 2018

39. The Pennsylvania State University CIC: An Integrated Building Process Model (1990). https://www.pennstatecic.org/uploads/5/1/2/1/51219339/tr_001_sanvido_1990_ibpm.pdf. Accessed 01 Jul 2018

40. Abbott, R.J.: Program design by informal English descriptions. Commun. ACM 26(11), 882-894 (1983)

41. NBIMS: National BIM Guide for Owners (2017). https://www.nibs.org/?nbgo. Accessed 01 Jul 2018

42. Johnson, R.E., Rosen, C.C., Chang, C.-H.: To aggregate or not to aggregate: steps for developing and validating higher-order multidimensional constructs. J. Bus. Psychol. 26(3), 241-248 (2011) 